\title{
Locked Lateral Patella Dislocation; the Role for the Skyline View in the Trauma Setting
}

\author{
Thomas Fleming ${ }^{1 *}$, Simon Bennet ${ }^{2}$, Andrew Tasker ${ }^{3}$, John McArthur ${ }^{4}$ and James Robinson ${ }^{5}$ \\ ${ }^{1}$ CT2 Trauma and Orthopaedics, Gloucestershire Hospitals NHS Foundation Trust, UK \\ ${ }^{2}$ Orthopaedic Registrar, Bristol Royal Infirmary, UK \\ ${ }^{3}$ Upper Limb Fellow, Frenchay Hospital, UK \\ ${ }^{4}$ Pelvic Fellow, Frenchay Hospital, UK \\ ${ }^{5}$ Orthopaedic Consultant, Frenchay Hospital, UK \\ Submission: January 12, 2017; Published: January 22, 2018 \\ *Corresponding author: Thomas Fleming, CT2 Trauma and Orthopaedics,Gloucestershire Hospitals NHS Foundation Trust, Alexandra House, \\ Cheltenham General Hospital, Sandford Rd, Cheltenham, GL53 7AN, United Kingdom, Email: tom.fleming1@nhs.net
}

\begin{abstract}
Acute traumatic dislocation of the patella is a common problem and most either spontaneously reduce or undergo successful closed reduction in the Emergency Department. We describe a rare case of an irreducible patella dislocation in a 15 year old boy following direct trauma. Intraoperative skyline views revealed lateral dislocation of the patella with the patella 'locked' in internal rotation. Closed reduction in theatre failed and open reduction was required. This case illustrates the benefit of the skyline view in the radiograph series following failed closed reduction, aiding the identification of atypical dislocations and osteochondral fracture fragments
\end{abstract}

Keywords: Patella; Dislocation; Trauma; Imaging

\section{Introduction}

Acute traumatic patella dislocation is a common problem presenting to Emergency Departments. Displacement is normally in the lateral coronal plane following indirect trauma. These dislocations may reduce spontaneously, or can be reduced by direct manipulation of the patella. Plain anteroposterior and lateral radiographs are obtained after manipulation to confirm reduction and assess for osteochondral fragments due to associated bony injury. A period of immobilisation is usually employed for comfort. Operative management is not usually required in the absence of osteochondral fragments.

We report a case of a locked lateral patella dislocation inverted around the vertical axis, with the knee locked in full extension. This rare traumatic dislocation presents a therapeutic problem which requires a general anaesthetic and commonly open reduction.

\section{Case Presentation}

A 15 year old boy presented to the Emergency Department following a football injury with a laterally directed blow to his left knee from the ground when diving to save a penalty. His knee was acutely painful and locked in full extension.

He had a background of autistic spectrum disorder and attention deficit and hyperactivity syndrome with no known predisposing factors for dislocation such as previous dislocation or hypermobility. Physical examination revealed a tender knee locked in extension with lateral patella displacement. A dislocated patella was visible on his anteroposterior radiograph (Figure 1).

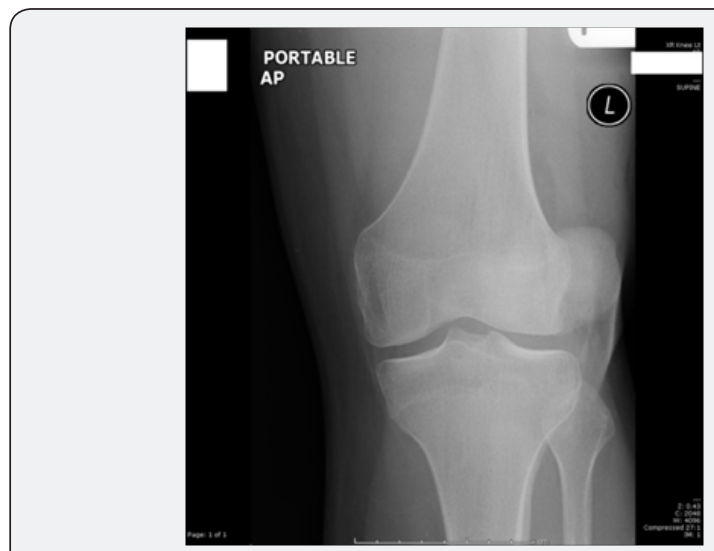

Figure 1: AP radiograph of the left knee showing a lateral dislocation of the patella.

Attempted closed reduction in the Emergency Department proved unsuccessful despite heavy sedation. He was referred to the on-call orthopaedic team for reduction in theatre. Intraoperative fluoroscopic skyline views showed the patella had rotated 90 degrees in the vertical plane, becoming wedged against the lateral femoral condyle (Figure 2). The anteromedial aspect of the patella was locked on the lateral femoral condyle. 


\section{Juniper Online Journal of Case Studies}

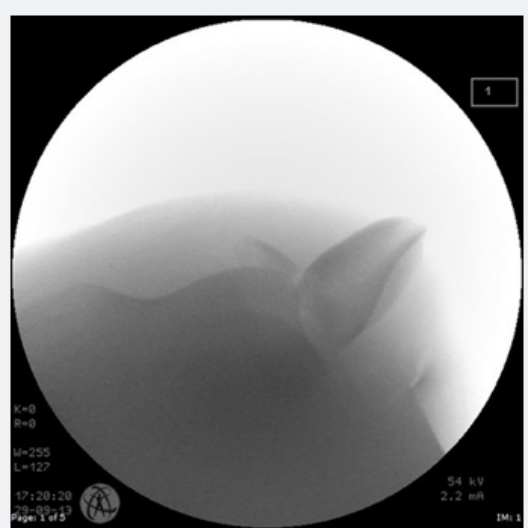

Figure 2: Skyline view in theatre demonstrating a lateral dislocation of the patella with rotation around the vertical axis.

Following unsuccessful closed reduction, the decision was made to proceed to open surgery via a medial parapatellar incision with subvastus approach. No loose fragments were seen on joint lavage but a small $1 \mathrm{~cm}$ free fragment of bone from the non-articular aspect of the patella was excised. There was also plastic deformation of medial patella border. The capsule and medial patellar retinaculum were reefed and repaired. Postreduction fluoroscopy showed the patella had been successfully reduced to its anatomical position in the trochlea groove (Figure 3).

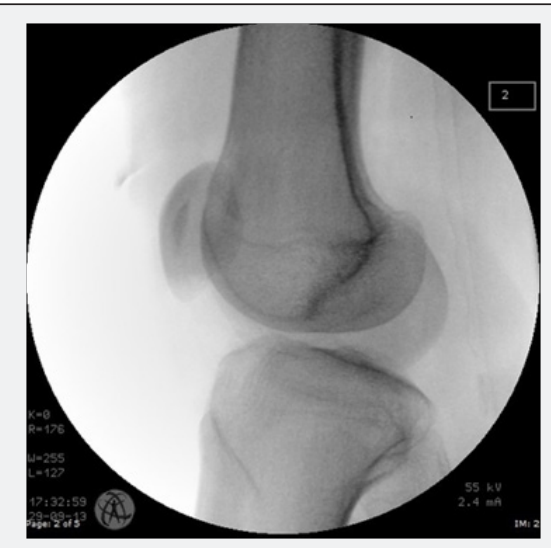

Figure 3: Post-reduction fluoroscopy showing the patella sitting in its anatomical position after open reduction.

The patient was immobilised in extension and converted to a hinged knee brace on the first post-operative day, allowing flexion from 0-90 degrees. Post-operative function was good with flexion to 90 degrees achieved by day 14 . Weight-bearing was permitted as tolerated and repeat skyline views after 4 weeks follow up showed no further osteochondral fragments and at this point the patient was referred for quadriceps rehabilitation.

\section{Discussion}

Acute patellar dislocation is the most frequent acute knee disorder in adolescents [1-3]. The peak incidence occurring between 15 and 19 years of age, with over half due to athletic activity [4]. Risk factors for acute patella dislocation include trochlea dysplasia shallow trochlear groove), female gender, hypermobility, patella alta (high riding patella) and a positive family history $[1,5,6]$.

Locked lateral patella dislocation with rotation around the vertical axis is a rare injury, with few reported cases. These injuries present a therapeutic problem in which reduction requires a general anaesthetic and frequently open surgery. Corso et al. [7] described such a dislocation in a 16 year old boy who sustained a laterally directed blow whilst wrestling. Michels et al. [8] document a case in a 16 year old girl that occurred whilst dancing, with no direct trauma. Whilst El Maraghy et al. [9] reported a similar dislocation sustained from a hyper-extension injury in a 30 year old woman. In all cases closed reduction failed and open operative reduction was required.

This injury represents high energy trauma and therefore necessitates this inspection. Open reduction of this injury provides the opportunity to remove or repair fragments of avulsed bone.

The use of Computerised Tomography (CT) in the acute setting to aid diagnosis of locked inverted patella has been advocated [8]. Nayak \& Bickerstaff [10] have previously suggested that the skyline view can aid in the detection of osteochondral fragments in patella dislocations. We believe this view also serves to highlight those cases of locked inverted patella, thus avoiding the radiation dose of a CT scan.

\section{Learning Points}

a) We believe that this case highlights the importance of the skyline view in acute traumatic dislocation of the patella, irreducible through closed reduction.

b) Including this as part of the radiographic series post failed reduction aids the detection of osteochondral fragments and atypical dislocations with rotation around the vertical axis

c) This avoids unnecessary further attempts at manipulation.

\section{References}

1. Beasley LS, Vidal AF (2004) Traumatic patellar dislocation in children and adolescents: treatment update and literature review. Curr Opin Pediatr 16(1): 29-36.

2. Nietosvaara Y, Aalto K, Kallio PE (1994) Acute patellar dislocation in children: incidence and associated osteochondral fractures. J Pediatr Orthop 14(4): 513-515.

3. Vahasarja V, Kinnunen P, Lanning P, Serlo W (1995) Operative realignment of patellar malalignment in children. J Pediatr Orthop 15(3): 281-285.

4. Waterman BR, Belmont PJ, Owens BD (2012) Patellar dislocation in the United States: role of sex, age, race, and athletic participation. J Knee Surg 25(1): 51-57.

5. Buchner M, Baudendistel B, Sabo D, Schmitt H (2005) Acute traumatic primary patellar dislocation: long-term results comparing conservative and surgical treatment. Clin J Sport Med 15(2): 62-66. 
6. Ofluoglu O, Yasmin D, Donthineni R, Muzaffler Y (2006) Superior dislocation of the patella with early onset patellofemoral arthritis: a case report and literature review. Knee Surg Sports Traumatol Arthrosc 14(4): 350-355.

7. Corso J, Thal R, Forman D (1992) Locked patellar dislocation with vertical axis rotation. A case report. Clin Orthop Relat Res 279: 190193.
8. Michels F, Pouliart N, Oosterlinck D (2008) Locked patellar dislocation: a case report. J Med Case Rep 2: 371.

9. ElMaraghy AW, Berry GK, Kreder HJ (2002) Irreducible lateral patellar dislocation with vertical axis rotation: case report and review of the literature. J Trauma 53:131-132.

10. Nayak RK, Bickerstaff DR (1995) Acute traumatic patellar dislocation: the importance of skyline views. Injury 26(5): 347-348.

\section{Your next submission with Juniper Publishers will reach you the below assets}

- Quality Editorial service

- Swift Peer Review

- Reprints availability

- E-prints Service

- Manuscript Podcast for convenient understanding

- Global attainment for your research

- Manuscript accessibility in different formats ( Pdf, E-pub, Full Text, Audio)

- Unceasing customer service

Track the below URL for one-step submission https://juniperpublishers.com/online-submission.php 